\title{
Pectin Gels Enriched with Dietary Fibre for the Development of Healthy Confectionery Jams
}

\author{
Lilian E. Figueroa ${ }^{1}$ and \\ Diego B. Genovese ${ }^{1,2 *}$
}

'Pilot Plant of Chemical Engineering, PLAPIQUI (UNS-CONICET), Camino La Carrindanga Km 7, AR-8000 Bahía Blanca, Argentina

2Department of Chemical Engineering, Universidad Nacional del Sur (UNS), Alem 1253, AR-8000 Bahía Blanca, Argentina

Received: 12 December 2017 Accepted: 6 April 2018

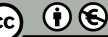

*Corresponding author:

Phone/ Fax: +542914861700;

E-mail: dgenovese@plapiqui.edu.ar

\section{SUMMARY}

The objective of this work is to evaluate the effect of the addition of dietary fibre from different sources (apple, bamboo, psyllium and wheat) and pectin mass fraction ( 0.4 and $0.5 \mathrm{~g} / 100 \mathrm{~g}$ ) on the physicochemical properties of pectin gels for the development of a novel, healthy product similar to a fruit confectionery jam. A mass fraction of $3 \mathrm{~g} / 100 \mathrm{~g}$ fibre was added to each pectin gel in order to declare the final product as a source of fibre. It was evident that pectin content, type of fibre, and their interaction had a significant effect on the viscoelastic and mechanical properties, and syneresis (water loss) of the gels. Since syneresis of the gel with $0.4 \mathrm{~g} / 100 \mathrm{~g}$ pectin was undesirably high, only studies of gels with $0.5 \mathrm{~g} / 100 \mathrm{~g}$ pectin followed from this point forward. Fibre addition had a reinforcing effect on the viscoelastic properties of these gels (wheat>psyllium >bamboo>apple). Psyllium-enriched gels did not suffer any syneresis, although they showed an undesirable "gummy" property, caused by low fracturability, high cohesiveness and low hardness. Then, in order to improve the organoleptic properties of the gels, we combined fibre from different sources in pairs (1:1). In general, fibre combination decreased the viscoelastic properties of the gels. However, mixing psyllium with other fibre produced a desirable effect on the mechanical properties of the gels, keeping the syneresis at $0 \mathrm{~g} / 100 \mathrm{~g}$. This indicates that $0.5 \mathrm{~g} / 100 \mathrm{~g}$ pectin and $1.5 \mathrm{~g} / 100 \mathrm{~g}$ psyllium fibre with $1.5 \mathrm{~g} / 100 \mathrm{~g}$ other fibre was the best formulation for the stability and texture of this product.

Key words: pectin, gels, dietary fibre, confectionery jams

\section{INTRODUCTION}

Dietary fibre consists of carbohydrate polymers with ten or more monomeric units, which are not hydrolyzed by endogenous enzymes in the human small intestine, and has physiological effects beneficial to health (1). It is widely accepted that consumption of dietary fibre reduces the incidence of various types of cancer, cardiovascular diseases, diabetes and constipation (2-7). According to the recommendations of the Food and Nutrition Board, Institute of Medicine of the USA National Academies (8), the daily requirement of dietary fibre is $21-25 \mathrm{~g}$ for women and $30-38 \mathrm{~g}$ for men, depending on their age. However, normal fibre intake is below those levels. This has challenged the food industry to incorporate fibre in traditional products, or to develop new fibre-rich products (9).

Fruit jams and marmalade are interesting commodities suitable for fibre addition because they are products for mass consumption. There are a few studies on the subject (1014). These works studied the effect of fibre addition on the physicochemical properties of the products. However, there are no systematic studies on the effect of fibre properties (solubility, shape, size, water absorption capacity, etc.) on gelation and structure of the model gel forming the matrix, which ultimately governs the physical properties of the product. This is one of the main objectives of the present work.

Jams and marmalade may be viewed as filler-matrix composite gels, where the matrix is a continuous phase made of a pectin gel, and the filler is a dispersed phase consisting of insoluble fruit pieces, pulp, or particles (15). According to the Argentine Food Code (16), a food product must contain at least $3 \mathrm{~g} / 100 \mathrm{~g}$ of dietary fibre to receive the label "source of fibre". 
Fruit jams contain dietary fibre, but this content is not known a priori, and it may not be enough for a food claim. Indeed, our own determinations made on commercial fruit jams (Table 1) showed that their fibre content was close to, but lower than 3 $\mathrm{g} / 100 \mathrm{~g}$. Therefore, the other main objective of this work is to incorporate the required amount of fibre in sugar-acid pectin gels, in order to develop healthy confectionery jams that can use the label claim "source of fibre". We used different types of fibre from fruit and non-fruit sources, some of their combinations, and different mass fractions of high methoxyl (HM) pectin, and studied their effect on the colour, syneresis, rheological and mechanical properties of the gels.

Table 1. Total, insoluble and soluble dietary fibre (TDF, IDF and SDF, respectively) contents and ratio of insoluble and total dietary fibre in pectin gels enriched with different types of fibre and in commercial jams

\begin{tabular}{lcccc}
\multirow{2}{*}{ Sample } & \multicolumn{3}{c}{$w /(\mathrm{g} / 100 \mathrm{~g})$} & \\
\cline { 2 - 4 } & TDF & IDF & SDF & \\
apple fibre & 3.60 & 1.85 & 1.76 & 0.513 \\
bamboo fibre & 4.12 & 2.87 & 1.26 & 0.695 \\
psyllium fibre & 3.53 & 3.27 & 0.26 & 0.928 \\
wheat fibre & 3.49 & 3.23 & 0.26 & 0.926 \\
plum jam & 2.96 & 1.19 & 1.77 & 0.403 \\
apricot jam & 2.37 & 1.15 & 1.22 & 0.485 \\
\hline
\end{tabular}

Non-covalent bonding of adjacent pectin chains (junction zones) causes the gelation of HM pectin, forming a three-dimensional network capable of retaining large amounts of water. A combination of hydrogen bonds and hydrophobic interactions stabilises junction zones (17). The purpose of fibre characterisation was to understand the effect of its physicochemical properties on the gelation process, and the final structure of the gel. A specific objective is to find the best formulation and preparation conditions in order to obtain fibre-enriched pectin gels with the appropriate stability, appearance, structure and consistency. Fibre-enriched pectin gels obtained in this work represent a novel product, similar to a confectionery fruit jam, with the advantages that it can be declared a source of fibre, and it may contain fibre from fruit and non-fruit sources.

\section{MATERIALS AND METHODS}

\section{Materials}

High methoxyl (HM) pectin was from Sigma-Aldrich, Merck (Steinheim, Germany), and food grade sucrose was from Ledesma (Jujuy, Argentina). Citrate buffer solution ( $\mathrm{pH}=3,0.1 \mathrm{M}$ ) consisted of sodium citrate dihydrate (Anedra, San Fernando, Argentina), anhydrous citric acid (Parafarm, Buenos Aires, Argentina) and distilled water. Dietary fibre from apple (Vitacel AF 400-30), wheat (Vitacel WF 101), and bamboo (Qualicel, CFF) was from JRS (Rosenberg, Germany). Dietary fibre from psyllium was from Konsyl Pharmaceuticals Inc. (Easton, MD, USA), and consisted of a mix of Plantago ovata seed husks (72 g/100 $\mathrm{g})$, maltodextrin $(27 \mathrm{~g} / 100 \mathrm{~g}$ ) and amorphous silica (1 g/100 g). Commercial fruit jams from plum (La Campagnola, Argentina) and apricot (Orieta, Córdoba, Argentina) were purchased in a local supermarket. lodine (Lugol's) solution was prepared by dissolving $1 \mathrm{~g}$ iodine and $2 \mathrm{~g}$ potassium iodine (both from Cicarelli, Santa Fe, Argentina) in $20 \mathrm{~mL}$ distilled water (18). Liquid Vaseline was from Ewe (Saladillo, Argentina).

Depending on the gel composition, the required mass fractions of ingredients were (in g/100 g): pectin 0.4 or 0.5 , solids 65 (sucrose 65 in control gels, or sucrose 62 and fibre 3 in enriched gels), filled up with the citrate buffer solution. A mass of $3 \mathrm{~g}$ fibre replaced the same amount of sucrose, and was added either pure, or in 1:1 combinations of two types of fibre: apple and bamboo, apple and wheat, apple and psyllium, bamboo and psyllium, and wheat and psyllium. Since pectin is also dietary fibre, this guarantees that the final fibre mass fraction in the samples was higher than $3 \mathrm{~g} / 100 \mathrm{~g}$ (except in the control sample).

The amount of used cosolute ( $65 \mathrm{~g}$ sucrose per $100 \mathrm{~g}$ gel) is the minimum mass fraction of soluble solids required for fruit jams, and the higher pectin mass fraction used $(0.5 \mathrm{~g} / 100 \mathrm{~g})$ is the maximum amount of gelling agent that can be added according to the Argentine Food Code (16). The lowest pectin level was determined empirically, observing that a pectin mass fraction lower than $0.4 \mathrm{~g} / 100 \mathrm{~g}$ in the resulting systems did not gel properly.

\section{Determination of fibre properties}

\section{Particle size distribution}

Particle size distributions (volume base) of dry and hydrated fibre were determined using a laser diffraction particle size analyzer model LA-950 (Horiba, Kyoto, Japan). Hydrated samples were prepared by dispersing approx. $0.1 \mathrm{~g}$ fibre in $50 \mathrm{~mL}$ distilled water and left overnight under agitation at $200 \mathrm{rpm}$ in a magnetic stirrer (Decalab SRL, Buenos Aires, Argentina). From each particle size distribution, mean diameter $\left(d_{\mathrm{m}}\right)$, and equivalent volume diameters at 10, 50 and 90 $\%\left(d_{10}, d_{50}\right.$ and $d_{90}$, respectively) were obtained. The span of each particle size distribution was calculated according to the following equation (19):

$$
\text { Span }=\frac{d_{90}-d_{10}}{d_{50}}
$$

\section{Swelling}

This property is defined as the ratio of the volume of the hydrated fibre (after immersion in excess water) to the initial mass of dry fibre. It was determined as follows $(20,21)$ : approx. $0.2 \mathrm{~g}$ dry fibre was weighed $\left(m_{\mathrm{d}}\right)$ and placed in a graduated tube with conical bottom. After the addition of $10 \mathrm{~mL}$ distilled water, the tube was manually agitated and the sample was allowed to settle during $24 \mathrm{~h}$ at room temperature. Afterwards, the final volume of the wet sample $\left(V_{w}\right)$ was measured. Then, swelling was calculated as:

$$
\text { Swelling }=\frac{V_{w}}{m_{d}}
$$


Water holding capacity and water retention capacity

Water holding capacity (WHC) and water retention capacity (WRC) are defined as the amount of water that remains bound to the fibre, without the application of any external force except gravity in the case of WHC, and after the application of an external force such as pressure or centrifugation in the case of WRC. They were determined as follows: approx. $1 \mathrm{~g}$ fibre was placed in a graduated tube with conical bottom. After the addition of $30 \mathrm{~mL}$ distilled water, the tube was manually agitated. Then, the following procedures were separately followed to determine WHC and WRC, respectively (20-22):

To determine WHC the sample was settling for $24 \mathrm{~h}$ at room temperature. Afterwards, the supernatant was eliminated, and the sample was drained in sintered glass G4 (borosilicate glass, IVA, Buenos Aires, Argentina) (previously weighed). After all the liquid was drained, the wet insoluble residue was weighed $\left(m_{w}\right)$, dried in oven at $102{ }^{\circ} \mathrm{C}$ overnight, and the dry residue was weighed $\left(m_{\mathrm{d}}\right)$. Then, WHC was calculated as follows:

$$
\mathrm{WHC}=\frac{m_{\mathrm{w}}-m_{\mathrm{d}}}{m_{\mathrm{d}}}
$$

For WRC determination, the tube was centrifuged at 1500 $\times g$ during $10 \mathrm{~min}$ in a Presvac DCS-16-RV centrifuge (Presvac SRL, Buenos Aires, Argentina). Afterwards, the supernatant was eliminated, and the sample was drained in sintered glass G4 (previously weighed). After all the liquid was drained, the wet insoluble residue was weighed $\left(m_{h}\right)$, dried in oven at 102 ${ }^{\circ} \mathrm{C}$ overnight, and the dry residue was weighed $\left(m_{\mathrm{s}}\right)$. Then, WRC was calculated as:

$$
\mathrm{WRC}=\frac{m_{\mathrm{h}}-m_{\mathrm{s}}}{m_{\mathrm{s}}}
$$

\section{Lugol's test}

In order to qualitatively determine the presence of starch in wheat fibre, a few drops of iodine (Lugol's) solution were added to the sample (18). The appearance of a blueish colour shows a positive result. One spoon of wheat fibre was placed in a beaker, distilled water was added and the dispersion was heated to the boiling point. After cooling, three drops of the Lugol's solution were added and the sample was allowed to settle for about $1 \mathrm{~h}$ until two phases were observed. Then the supernatant and the sediment were separated by decantation and their colour was measured as described in section Colour measurement. The same procedure was applied to commercial starch and wheat flour samples. All measurements were done in duplicate.

\section{Gel preparation}

For gels without fibre other than pectin (control gels), pectin was dispersed in the buffer solution and left overnight under agitation. Part of sucrose (15 times the mass of the pectin) was initially added to this dispersion in order to enhance pectin hydration (23). Next day, the rest of the sucrose was slowly added to the mix, and simultaneously heated in a water bath on a hotplate stirrer (Decalab SRL, Buenos Aires, Argentina) up to approx. $90^{\circ} \mathrm{C}$. This hot dispersion of pectin and sugar was later transferred to the different measurement devices, where it gelled upon cooling. The same procedure was followed for gels with fibre (fibre-enriched gels) as for control gels, with the difference that the fibre was added after 2 $\mathrm{h}$ of pectin hydration.

For each sample, the hot dispersion of pectin and sugar was prepared three times, so that all the following measurements were made in triplicate (unless stated otherwise).

\section{Dietary fibre content determination}

Standard AOAC official method 991.43 (24) was used to determine total and insoluble dietary fibre in fibre-enriched gels with $0.5 \mathrm{~g} / 100 \mathrm{~g}$ pectin and two commercial fruit jams, in duplicate. Briefly, each sample was dispersed in 2-(N-morpholino)ethanesulfonic acid/Tris(hydroxymethyl) aminomethane (MES/Tris) buffer (0.05 M, pH=8.2), and underwent sequential enzymatic digestion by heat-stable a-amylase, protease and amyloglycosidase. For total dietary fibre (TDF), enzyme digestate was treated with alcohol to precipitate soluble dietary fibre before filtering, and total dietary fibre (TDF) residue was washed with alcohol and acetone, dried and weighed. For insoluble dietary fibre (IDF) enzyme digestate was filtered, and the residue (IDF) was washed with warm water, dried and weighed. TDF and IDF residue values were corrected for protein, ash and blank, due to buffer salt and enzyme addition to the samples. Finally, soluble dietary fibre (SDF) was calculated from the difference:

$$
\text { SDF=TDF-IDF }
$$

\section{Rheological property measurement}

Rheological properties were measured by Paar Physica MCR 301 rheometer (Anton Paar $\mathrm{GmbH}, \mathrm{Graz}$, Austria) using cone and plate geometry (diameter $d=50 \mathrm{~mm}$, angle $\Theta=1^{\circ}$ ), with temperature controlled by a Peltier system. For each sample, an aliquot of the hot dispersion was poured on the rheometer plate, previously conditioned at $90^{\circ} \mathrm{C}$. Next, the cone was lowered to the measuring position, excess sample was removed, and the exposed sample surface was covered with liquid Vaseline to avoid sample dehydration during measurement. Elastic $\left(G^{\prime}\right)$ and viscous $\left(G^{\prime \prime}\right)$ moduli were determined by dynamic oscillatory measurements at $0.5 \%$ strain, which was previously found to be within the linear viscoelastic range (LVR) of the samples. Each measurement was performed in three steps: (i) cooling from 90 to $20^{\circ} \mathrm{C}$ (at constant angular frequency $\omega=1 \mathrm{rad} / \mathrm{s}$ ), (ii) ageing at $20^{\circ} \mathrm{C}$ during $120 \mathrm{~min}$ (at $\omega=1 \mathrm{rad} / \mathrm{s}$ ), and (iii) frequency sweeps from 0.1 to $100 \mathrm{rad} / \mathrm{s}$ (at $t=20^{\circ} \mathrm{C}$ ).

Cone and plate geometry was selected due to its uniform shear rate along the sample. However, additional measurements were performed with parallel plates $(d=50 \mathrm{~mm}$, gap 
$w=2 \mathrm{~mm}$ ) in order to check that there was no jamming of fibre particles in the narrow zone of the cone and plate geometry affecting the measurements. For these additional measurements, the hot dispersion of pectin and sugar with psyllium fibre (the largest in size) was poured to the rheometer and cooled from 90 to $20^{\circ} \mathrm{C}$ using the Peltier system. Then, the LVR was determined and frequency sweeps were performed as previously mentioned.

\section{Mechanical property determination}

Mechanical properties were determined in a TA Plus texture analyzer (Lloyd Instruments, Ametek, Albany, NY, USA) fitted with a $50 \mathrm{~N}$ load cell, applying a texture profile analysis (TPA) test, which consists of two compression cycles of the sample up to half of its initial height.

For each sample, part of the hot dispersion was poured in 5 cylindrical acrylic moulds ( $h=33 \mathrm{~mm}, d=33 \mathrm{~mm}$ ) with a plastic film base, and allowed to cool down to room temperature for approx. $2 \mathrm{~h}$. Next, the moulds were placed in the fridge (at $4.5^{\circ} \mathrm{C}$ ) overnight. Next day, the moulds were withdrawn from the fridge $2 \mathrm{~h}$ before measurement, to allow the gels to warm up to room temperature. When the gels were removed from the moulds, most of them reached a height of approx. $30 \mathrm{~mm}$. These gels were compressed to an extension of $15 \mathrm{~mm}$, using a cylindrical probe $(d=70.6 \mathrm{~mm})$, at a crosshead speed of $1 \mathrm{~mm} / \mathrm{s}$. A few gels flattened to approx. $20 \mathrm{~mm}$ height after being removed from the moulds, and these gels were compressed to an extension of $10 \mathrm{~mm}$, in order to respect the 50 $\%$ compression/initial height ratio.

From each TPA test force vs. time curve six parameters were obtained, namely hardness, determined as the maximum peak force during the first compression cycle; fracturability, determined as the force at the first significant sample rupture during the first compression cycle; adhesiveness, calculated as the negative area under the force curve after the first compression cycle; cohesiveness, calculated as the ratio of the positive area under the force curve of the first compression cycle to the one of the second cycle; springiness, calculated as the ratio of the deformation during positive forces of the second compression cycle to the one of the first cycle; and gumminess, calculated as the product of hardness times cohesiveness (25).

\section{Syneresis determination}

Syneresis was determined as the water loss from the gels during the first $24 \mathrm{~h}$ after texture measurement, at room temperature. The purpose was to use samples with damaged structure, as fruit jams in domestic use (after extraction from the jar). External factors such as mechanical stress or heating can initiate or accelerate syneresis, and even a small mechanical intrusion into the pectin gel, like taking some jam from a jar, can start this process (26). Using the samples after the texture measurement guarantees that all gels have suffered the same deformation (two compression cycles, $50 \%$ strain), and consequently similar structural damage. These samples were called squeezed gels.

For each sample, two squeezed gels were used, each one placed on a Büchner funnel with a filter paper at the base (previously weighed). The funnel with the gel was weighed and covered with a plastic film to avoid dehydration. Then the funnel was inserted in an Erlenmeyer flask (previously weighed) to collect the liquid lost from the gel by gravity. After $24 \mathrm{~h}$, the funnel with the drained gel and the Erlenmeyer flask with the liquid were weighed. Syneresis was calculated as:

$$
\text { Syneresis }=\frac{m_{\mathrm{i}}-m_{\mathrm{f}}}{m_{\mathrm{i}}}
$$

where $m_{\mathrm{i}}$ and $m_{\mathrm{f}}$ are the initial and final mass of the squeezed gel, respectively.

\section{Colour measurement}

Colour of the gels was measured in a HunterLab UltraScan XE spectrophotometric colorimeter (Hunter Associates Laboratory Inc., Reston, VA, USA). For each sample, part of the hot dispersion was poured in two glass cells $(10 \mathrm{~mm}$ thickness), and allowed to cool down during $24 \mathrm{~h}$. Reflected colour (specular component excluded, D65 illuminant, $10^{\circ}$ observer angle) was measured. Results were expressed in terms of the CIELab scale parameters: $L^{*}$ (lightness, $0=$ black, $100=$ white), $a^{*}$ (greenness $(-)$, redness $\left.(+)\right)$ and $b^{*}$ (blueness $(-)$, yellowness $(+))$. Measurements were performed only on gels with pectin $0.5 \mathrm{~g} / 100 \mathrm{~g}$, considering that a $0.1 \mathrm{~g} / 100 \mathrm{~g}$ change in pectin mass fraction would not affect gel colour.

\section{Light microscopy}

The microstructure of wheat fibre (both dry and hydrated) and fibre-enriched gels was analyzed with a Primo Star light microscope (Carl Zeiss, Göttingen, Germany). Hydrated wheat fibre was prepared as for the particle size distribution measurements. Then, aliquots of both dry and hydrated wheat fibre were placed in two glass slides, respectively. For each fibre-enriched gel, one drop of the hot dispersion was placed on a glass slide, and covered before gelation. Optical magnification of $40 \times$ (total magnification of $80 \times$ ) was used for gels with apple, bamboo and wheat fibre, and 10x magnification (20x total magnification) for wheat fibre and gels with psyllium fibre. Measurements were performed only on gels with pectin $0.5 \mathrm{~g} / 100 \mathrm{~g}$, given that pectin network is not visible under these conditions, and therefore its mass fraction is irrelevant.

\section{Statistical analysis}

Experimental data were statistically analyzed applying first a two-factor (pectin content and type of fibre) ANOVA, followed by a single-factor (type of fibre) ANOVA to analyze the effect of fibre combination. Tukey's tests served to compare 
mean values at a significance level of 0.05 , using the InfoStat v. 2014 software (27). In all cases, Box-Cox diagnosis tests were previously performed to check for ANOVA assumptions (normality and homoscedasticity), and data were transformed when necessary, using Design-Expert v. 7.0.0 software (28).

\section{RESULTS AND DISCUSSION}

\section{Fibre characterization}

All samples presented a monomodal particle size distribution, with a small shoulder in some cases, and the same change in the shape of the distribution after fibre hydration (data not shown). Calculated mean diameter, $d_{\mathrm{m}}$, and span of the particle size distributions of dry and hydrated fibre are shown in Table 2. Among dry fibre, psyllium clearly had the largest diameter, followed by wheat, apple and bamboo. After hydration, there was an increase in the $d_{m}$ of apple (+223 $\%)$, bamboo (+14\%) and psyllium (+70\%) fibre, but a decrease in the $d_{m}$ of wheat fibre $(-35 \%)$, resulting in the following order of hydrated fibre size: psyllium $>$ apple $>$ wheat $>$ bamboo. On the other hand, hydration did not seem to affect the span (a measure of the width of the size distributions) significantly. The increases in particle size were attributed to fibre water absorption and swelling, as discussed next. The decrease in $d_{\mathrm{m}}$ of wheat fibre was attributed to the dispersion of particle aggregates during hydration. This was confirmed by analyzing the microstructure of dry and hydrated wheat fibre. Fig. 1 a shows the presence of numerous particle aggregates in the dry wheat fibre, while these particles appear to be more scattered in the hydrated sample (Fig. 1b).

Regarding the hydration properties of the fibre (Table 2), swelling measures the packed matrix bulking potential, and WHC and WRC measure the water holding and retention (after centrifugation) by the insoluble matrix, respectively. It is observable that psyllium and apple fibre showed the highest values of the hydration properties (swelling, WHC and WRC), while bamboo and wheat fibre showed the lowest values. These results were mostly in agreement with the changes in particle size after hydration, although not directly proportional to them. The low swelling of wheat fibre is also observable by comparing the individual particles of Figs. $1 \mathrm{a}$ and $1 \mathrm{~b}$. Finally, it should be noted that most of the hydration property values were of the same order but somehow different from those obtained in other works $(9,22,29)$. This was attributed to some procedure differences between the techniques
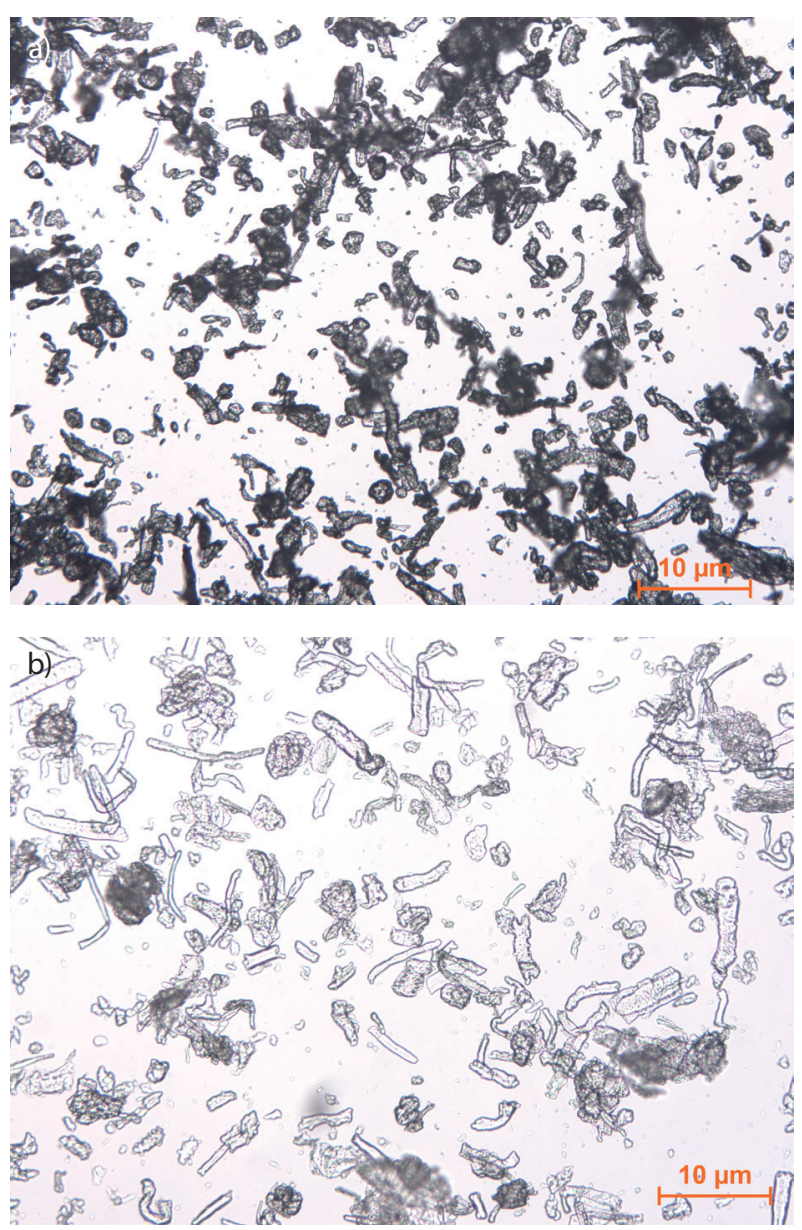

Fig. 1. Micrographs of wheat fibre: a) dry, and b) hydrated

used to determine the hydration properties, and also probably due to differences in the chemical and/or physical structure of the used fibre, which are known to affect the hydration properties $(30,31)$.

The Lugol's test was positive for the presence of starch in wheat fibre, since the dispersion of this fibre turned blueish after the addition of the iodine solution. The blue tone was more evident in the sediment than in the supernatant, although colour measurements gave values of $b<0$ in both phases (data not shown), confirming the blue colouration and the presence of starch in wheat fibre. Lugol's test on commercial starch and wheat flour also gave positive results, as expected, with a more intense blue colouration (lower $b$ values, data not shown) due to their higher starch content.

Table 2. Particle size distribution and hydration properties of different types of fibre

\begin{tabular}{|c|c|c|c|c|c|c|c|}
\hline \multirow{2}{*}{ Fibre } & \multicolumn{2}{|c|}{ Dry } & \multicolumn{2}{|c|}{ Hydrated } & \multirow{2}{*}{ Swelling/(mL/g) } & \multirow{2}{*}{$\mathrm{WHC} /(\mathrm{g} / \mathrm{g})$} & \multirow{2}{*}{$W R C /(g / g)$} \\
\hline & $d_{m} / \mu \mathrm{m}$ & Span & $d_{m} / \mu m$ & Span & & & \\
\hline apple & $69.5 \pm 0.1$ & 2.0 & $223.8 \pm 3.7$ & 2.3 & $14.8 \pm 0.6$ & $9.2 \pm 0.2$ & $6.9 \pm 0.9$ \\
\hline bamboo & $36.5 \pm 0.5$ & 1.7 & $41.5 \pm 1.3$ & 1.8 & $11.2 \pm 1.7$ & $4.2 \pm 0.2$ & $3.4 \pm 0.1$ \\
\hline psyllium & $287.6 \pm 14.7$ & 1.6 & $486.6 \pm 16.8$ & 2.1 & $37.3 \pm 3.5$ & $30.7 \pm 1.1$ & $28.6 \pm 1.2$ \\
\hline wheat & $89.5 \pm 1.1$ & 3.1 & $57.9 \pm 2.1$ & 2.9 & $10.2 \pm 0.9$ & $4.9 \pm 0.5$ & $4.9 \pm 0.4$ \\
\hline
\end{tabular}

$d_{\mathrm{m}}=$ median diameter, $\mathrm{WHC}=$ water holding capacity, $\mathrm{WRC}=$ water retention capacity 


\section{Dietary fibre content}

Table 1 shows the total, insoluble and soluble dietary fibre content (TDF, IDF and SDF, respectively) of fibre-enriched gels (with pectin $0.5 \mathrm{~g} / 100 \mathrm{~g}$ ) and two commercial samples of fruit jam. It is observable that TDF content of both commercial jams was lower than $3 \mathrm{~g} / 100 \mathrm{~g}$. On the other hand, TDF content of fibre-enriched gels was about $0.5 \mathrm{~g} / 100 \mathrm{~g}$ above the $3 \mathrm{~g} / 100 \mathrm{~g}$ target value. This was due to the contribution of the pectin, which is considered to be dietary fibre (32). Consequently, only the fibre-enriched gels (but not the commercial jams studied) could be declared as a "source of fibre". It is also evident that the insoluble fraction of dietary fibre (IDF/TDF) in commercial jams was lower than that of fibre-enriched gels, and only comparable to the value of gels enriched with apple fibre, which is also from fruit source (and the only one studied in this work). Therefore, this suggests that another consequence of using non-fruit fibre is the increase of the IDF/TDF fraction in the final product. The insoluble fraction of fibre has been related to the intestinal regulation, whereas the soluble fraction is associated with the decrease in cholesterol levels and the absorption of intestinal glucose (9).

\section{Characterization of fibre-enriched gels}

The first part of each of the following sections will discuss the effect of pectin content $(0.4$ and $0.5 \mathrm{~g} / 100 \mathrm{~g})$, fibre addition and type of fibre (apple, bamboo, psyllium and wheat) on the physical properties of fibre-enriched gels.

Simple observation of the fibre-enriched gels reveals that some of their organoleptic properties may not be suitable for the development of healthy confectionery jams; for example gels enriched with apple fibre were probably too dark, gels enriched with bamboo and wheat fibre had a floury mouthfeel, and as previously mentioned, gels enriched with psyllium fibre were too "gummy". In order to improve the organoleptic properties of the fibre-enriched gels, the fibre was mixed or combined in pairs at the ratio 1:1, namely apple and bamboo, apple and wheat, apple and psyllium, bamboo and psyllium, and wheat and psyllium.

The second part of each of the following sections will explain the effect of fibre combination on the physical properties of fibre-enriched gels. The effect of each fibre pair was compared to the effect of each single fibre. It should be noted that not all the possible fibre combinations were studied, but only those that were thought to improve the organoleptic properties of the product.

\section{Rheological properties of fibre-enriched gels}

No significant differences were found between the viscoelastic properties measured with the cone and plate and parallel plate geometries. This indicates that there was no particle jamming in cone and plate measurements, and consequently the rest of the rheological measurements were performed with this geometry. During the three steps of the rheological test (cooling, ageing, and frequency sweep), $G^{\prime}$ was higher than $G^{\prime \prime}$ in all samples (data not shown), meaning that the solid character prevailed in all gels, even at high temperatures. The last 10 points of each ageing curve (data not shown) were averaged and considered the equilibrium values of $G^{\prime}$ and $G^{\prime \prime}$ for each sample (Table 3). These values were used to statistically compare the samples.

Table 3. Equilibrium elastic $\left(G^{\prime}\right)$ and viscous $\left(G^{\prime \prime}\right)$ moduli after ageing, colour parameters $\left(L^{*}, a^{*}, b^{*}\right)$ and syneresis of the gels with pectin $0.4 \mathrm{~g} / 100$ $\mathrm{g}$ (marked with 1) and $0.5 \mathrm{~g} / 100 \mathrm{~g}$ (marked with 2), and gels enriched with different types of fibre and combination of two types of fibre (1:1)

\begin{tabular}{|c|c|c|c|c|c|c|}
\hline Sample & $G^{\prime} / P a$ & $G^{\prime \prime} / \mathrm{Pa}$ & $L^{*}$ & $a^{*}$ & $b^{*}$ & $\begin{array}{c}\text { Syneresis/ } \\
\text { (g/100 g) }\end{array}$ \\
\hline C1 & $(51.9 \pm 5.2)^{\mathrm{a}}$ & $(6.11 \pm 0.72)^{\mathrm{a}}$ & - & - & - & $(17.8 \pm 0.5)^{\mathrm{e}}$ \\
\hline $\mathrm{A} 1$ & $(1022 \pm 262)^{c, d}$ & $(144 \pm 53)^{c}$ & - & - & - & $(11.4 \pm 1.4)^{d}$ \\
\hline B1 & $(151 \pm 89)^{\mathrm{b}}$ & $(18.8 \pm 6.7)^{b}$ & - & - & - & $(17.8 \pm 0.4)^{\mathrm{e}}$ \\
\hline P1 & $(434 \pm 88)^{c}$ & $(142 \pm 27)^{c}$ & - & - & - & - \\
\hline W1 & $(640 \pm 235)^{c, d}$ & $(131 \pm 42)^{c}$ & - & - & - & $(20.1 \pm 1.4)^{f}$ \\
\hline $\mathrm{C} 2$ & $(723 \pm 65)^{c, d}$ & $(130 \pm 3)^{c}$ & $(69.4 \pm 0.6)^{\mathrm{e}}$ & $(-2.1 \pm 0.1)^{\mathrm{a}}$ & $(13.5 \pm 0.5)^{\mathrm{b}, \mathrm{c}}$ & $(9.0 \pm 0.4)^{\mathrm{c} d \mathrm{~d}}$ \\
\hline $\mathrm{A} 2$ & $(996 \pm 304)^{c, d, B, C}$ & $(197 \pm 47)^{C, B, C}$ & $(12.7 \pm 0.6)^{\mathrm{a}, \mathrm{A}}$ & $(14.2 \pm 0.7)^{\mathrm{d}, \mathrm{E}}$ & $(14.6 \pm 0.6)^{\mathrm{C}, \mathrm{E}}$ & $(6.0 \pm 0.8)^{b, B}$ \\
\hline B2 & $(1370 \pm 615)^{d, C, D}$ & $(220 \pm 72)^{C, B, C}$ & $(46.5 \pm 0.6)^{\mathrm{b}, \mathrm{F}}$ & $(-1.1 \pm 0.1)^{\mathrm{b}, \mathrm{A}}$ & $(11.6 \pm 0.4)^{\mathrm{a}, \mathrm{D}}$ & $(7.4 \pm 0.4)^{b, c, B}$ \\
\hline P2 & $(3587 \pm 958)^{e, D, E}$ & $(903 \pm 490)^{d, D, E}$ & $(37.7 \pm 0.8)^{\mathrm{d}, \mathrm{D}}$ & $(3.6 \pm 0.4)^{c, c}$ & $(20.1 \pm 0.1)^{\mathrm{d}, \mathrm{F}}$ & - \\
\hline W2 & $(9460 \pm 1467)^{\mathrm{f}, \mathrm{E}}$ & $(2570 \pm 461)^{\mathrm{e}, \mathrm{E}}$ & $(42.4 \pm 0.8)^{\mathrm{C}, \mathrm{E}}$ & $(-0.71 \pm 0.04)^{b, A}$ & $(12.2 \pm 0.8)^{a, b, D}$ & $(6.7 \pm 0.4)^{\mathrm{b}, \mathrm{B}}$ \\
\hline AB2 & $(157 \pm 45)^{\mathrm{A}}$ & $(21.5 \pm 5.9)^{\mathrm{A}}$ & $(17.9 \pm 0.3)^{\mathrm{B}}$ & $(9.0 \pm 0.3)^{\mathrm{D}}$ & $(8.9 \pm 0.3)^{A, B, C}$ & $(13.2 \pm 1.3)^{c}$ \\
\hline AW2 & $(436 \pm 51)^{A, B}$ & $(78.7 \pm 19.3)^{B}$ & $(17.2 \pm 0.4)^{\mathrm{B}}$ & $(9.0 \pm 0.3)^{\mathrm{D}}$ & $(8.3 \pm 0.2)^{A, B}$ & $(16.8 \pm 0.5)^{\mathrm{D}}$ \\
\hline AP2 & $(737 \pm 405)^{B, C}$ & $(168 \pm 119)^{B, C}$ & $(17.3 \pm 0.1)^{\mathrm{B}}$ & $(9.8 \pm 0.8)^{\mathrm{D}}$ & $(8.1 \pm 0.7)^{\mathrm{A}}$ & - \\
\hline BP2 & $(724 \pm 340)^{B, C}$ & $(144 \pm 70)^{\mathrm{B}, \mathrm{C}}$ & $(32.6 \pm 0.3)^{C}$ & $(1.7 \pm 0.1)^{\mathrm{B}}$ & $(10.0 \pm 0.2)^{c}$ & - \\
\hline WP2 & $(1642 \pm 553)^{C, D}$ & $(336 \pm 128)^{C, D}$ & $(32.5 \pm 0.8)^{c}$ & $(1.5 \pm 0.3)^{\mathrm{B}}$ & $(9.5 \pm 0.4)^{B, C}$ & - \\
\hline
\end{tabular}

Samples with a common letter are not significantly different ( $p>0.05)$ : lower case letters compare the first ten samples of the first column (from C1 to W2), upper case letters compare the last nine samples of the first column (from A2 to WP2); $C=$ control gel (without fibre), $A=a p p l e$, $\mathrm{B}=$ bamboo, $\mathrm{P}=$ psyllium and $\mathrm{W}=$ wheat fibre 
Fig. 2a shows the evolution of $G^{\prime}$ during sample cooling from 90 to $20^{\circ} \mathrm{C}$. It is evident that all curves followed a similar trend, with an increase in $G^{\prime}$ during cooling due to sample gelation (33). As expected, $G^{\prime}$ of the gels with the same type of fibre was higher when the pectin content was higher, because the gel network is denser and has more junction zones (34), resulting in a stronger pectin network, and a firmer gel structure. On the other hand, at fixed pectin content, fibre addition increased $G^{\prime}$ in comparison with the control gel. This could be attributed to one or both of these reasons: (i) the soluble fraction of the fibre had a favourable effect on the gelation mechanism, contributing to the aqueous phase composition, and/or (ii) the insoluble fraction of the fibre (fibre particles) acted as a filler of the gel, reinforcing its structure (35).

Both $G^{\prime}$ (Fig. 2b) and $G^{\prime \prime}$ (data not shown) presented some dependence on the angular frequency indicating a relaxation process, typical of weak gels (36). Again, $G^{\prime}$ increased at increasing pectin content and, at a fixed pectin content, it increased with the addition of fibre. It is known that if there is good affinity between the particles and the gel matrix, the addition of particles increases $G^{\prime}$ of the gel, and this increase would depend on particle characteristics (35).

Statistical analysis indicated that both $G^{\prime}$ and $G^{\prime \prime}$ values required a logarithmic transformation. We found that the pectin content, the type of fibre, and the interaction between both factors had significant effect on the viscoelastic properties of the gels. There were significant differences between 0.4 and $0.5 \mathrm{~g} / 100 \mathrm{~g}$ of pectin in the gels with each type of fibre, except for those with apple fibre. Fibre addition had a significant effect on all gels with lower pectin content (compared to the control), while in the gels with higher pectin content, fibre addition had a significant effect on viscoelastic properties only of those with wheat and psyllium fibre (compared to control). In gels with pectin $0.5 \mathrm{~g} / 100 \mathrm{~g}$, the addition of apple and bamboo fibre gave the two weakest gels, while wheat and psyllium fibre gave the two strongest gels. The highest reinforcing effect produced by wheat fibre was attributed to the presence of starch (as confirmed by Lugol's test), which most probably gelatinized during the thermal treatment of the sample. For some reason, this reinforcing effect was not as strong at the lower pectin mass fraction. The reinforcing effect of psyllium fibre (second highest) was attributed to its hydration properties (swelling, WHC and WRC) and hydrated $d_{m}$, which showed the highest values among the studied fibre (Table 2), and its ability to form a clear gelatinous mass at $2 \mathrm{~g} / 100 \mathrm{~g}$ mass fraction (37).

Gels enriched with fibre mixtures showed an increase of $G^{\prime}$ (Fig. 2c) during cooling from 90 to $20^{\circ} \mathrm{C}$, due to gelation. Fig. 2 d shows that $G^{\prime}$ gradually increased with the angular frequency in all gels with mixed fibre. Both types of behaviour were similar to those observed for the gels with single type of fibre.
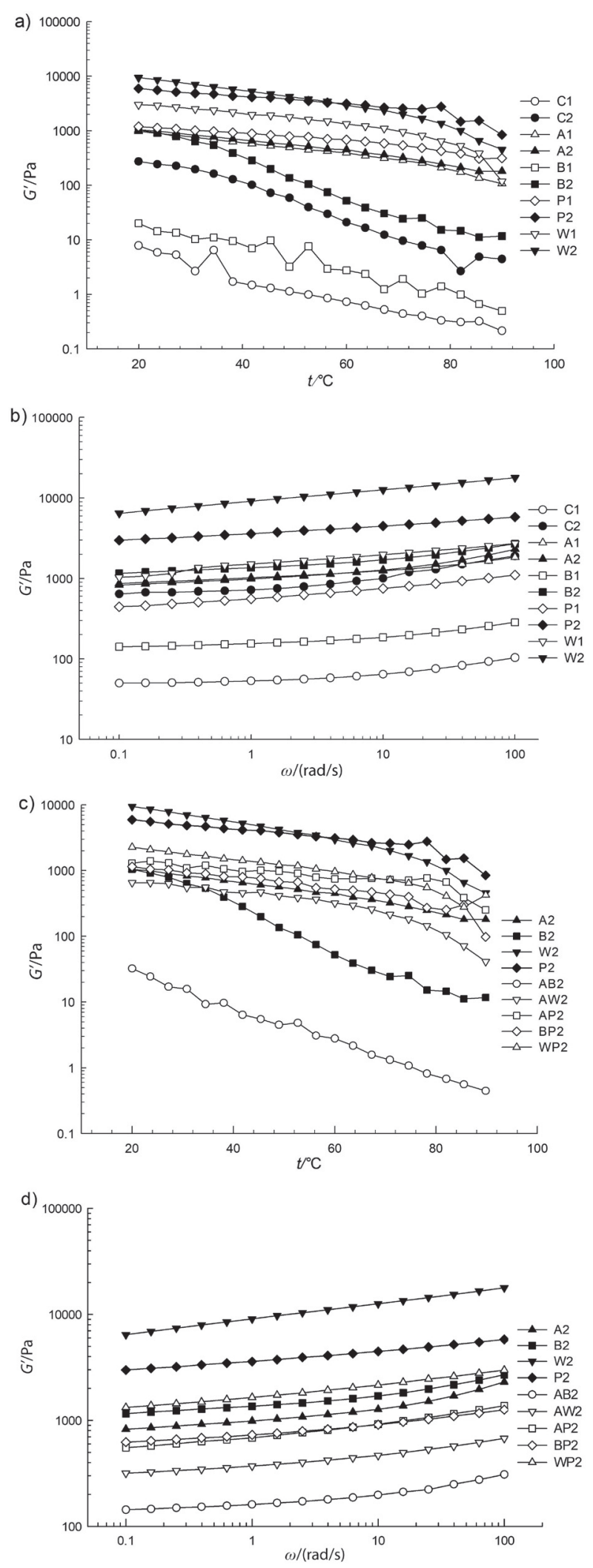

Fig. 2. a) Elastic modulus $\left(G^{\prime}\right)$ vs temperature $(t)$ during cooling, and b) $G^{\prime}$ vs angular frequency $(\omega)$ of samples with pectin $0.4 \mathrm{~g} / 100 \mathrm{~g}$ (marked with 1) and $0.5 \mathrm{~g} / 100 \mathrm{~g}$ (marked with 2), enriched with apple (A), bamboo (B), psyllium (P) or wheat (W) fibre, and control sample without fibre (C), C) $G^{\prime} v s t$ during cooling, and d) $G^{\prime} v s \omega$ of samples with pectin $0.5 \mathrm{~g} / 100 \mathrm{~g}$ enriched with one type of fibre (A, B, P or W), and fibre combinations (1:1) 
Statistical analysis indicated that both $G^{\prime}$ and $G^{\prime \prime}$ values required a logarithmic transformation. It was evident that combination of fibre had a significant effect on the viscoelastic properties, G' and G". Comparisons by Tukey's test showed that the mix of apple and bamboo fibre gave a gel with significantly lower $G^{\prime}$ and $G^{\prime \prime}$ values than the gels with each single fibre (Table 3), indicating that the interaction between apple and bamboo was negative for pectin network and gel structure. Second, gels with combined apple and wheat fibre or apple and psyllium fibre did not show significant differences from the gels with apple fibre alone, but had $G^{\prime}$ and $G^{\prime \prime}$ values significantly lower than gels with wheat and psyllium alone, indicating that apple fibre dominated the viscoelastic properties of the gels when it was mixed with wheat and psyllium fibre. Third, gels with the mixture of wheat and psyllium fibre were not significantly different from the gels with psyllium alone, but had $G^{\prime}$ and $G^{\prime \prime}$ values significantly lower than gels with wheat alone, indicating that psyllium fibre dominated the viscoelastic properties when it was mixed with wheat fibre. Finally, gels with the mixture of bamboo and psyllium fibre were not significantly different from gels with bamboo fibre alone, but had $G^{\prime}$ and $G^{\prime \prime}$ values significantly lower than gels with psyllium fibre alone, indicating that bamboo fibre dominated the viscoelastic properties when it was mixed with psyllium fibre.

In general, it can be said that combinations of fibre had a negative effect (sometimes significant) on the viscoelastic properties, compared to the single fibre. It can also be noted that fibre that had the lowest reinforcing effect (apple and bamboo) dominated the viscoelastic properties when mixed with fibre that had the strongest reinforcing effect (psyllium and wheat). Since samples with apple and bamboo fibre had the highest mass fraction of SDF (Table 1), it seems that the effect of SDF on pectin gelation prevailed over the filler reinforcing effect of IDF, which predominates in samples with psyllium and wheat fibre. When fibre that gave the weakest gels (apple and bamboo) were mixed together, the resulting gel was even weaker. When fibre that gave the strongest gels (psyllium and wheat) were mixed together, the fibre with the lowest reinforcing effect (psyllium) prevailed. This was attributed to a negative interaction between the types of fibre, probably due to a competition for the available water.

\section{Mechanical properties of fibre-enriched gels}

Analyzing the force-time curves obtained from the TPA test performed on gels (Fig. 3), it was obvious that decreasing pectin content and adding fibre to the gels both shifted the curves down, although pectin content had a more remarkable effect on the magnitude and shape of the curves. Samples that showed the second peak earlier were those compressed to $20 \mathrm{~mm}$ instead of $30 \mathrm{~mm}$, as explained in the section Mechanical property determination.

Table 4 shows the mechanical parameters obtained from the force vs time curves. Statistical analysis indicated that gumminess data required a square root transformation, and
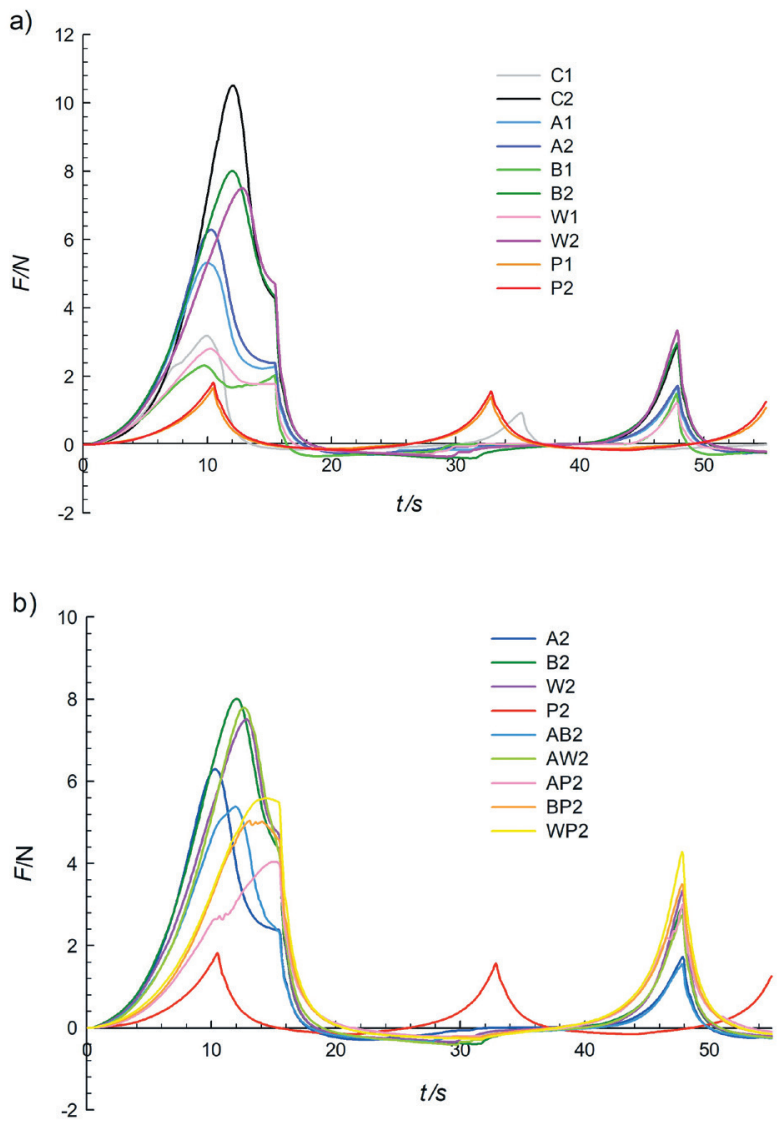

Fig. 3. Force $(F)$ vs time $(t)$ curves during texture profile analysis (TPA) test: a) gels with pectin $0.4 \mathrm{~g} / 100 \mathrm{~g}$ (marked with 1) and $0.5 \mathrm{~g} / 100 \mathrm{~g}$ (marked with 2), enriched with apple (A), bamboo (B), psyllium (P) or wheat (W) fibre, and control sample without fibre (C), b) gels with pectin $0.5 \mathrm{~g} / 100 \mathrm{~g}$ enriched with one type of fibre (A, B, P or W), and fibre combinations (1:1)

springiness data required an inverse square root transformation. It was found that pectin content, type of fibre, and the interaction between both factors had a significant effect on the mechanical properties of the gels. An increase in pectin content produced a significant increase in hardness, fracturability and gumminess in gels with bamboo and wheat fibre, and in controls, while the other parameters (cohesiveness, adhesiveness and springiness) were not significantly affected. It should be noted that gels with psyllium fibre did not show fracturability.

For both pectin mass fractions fibre addition did not have a significant effect on gel gumminess. Psyllium fibre caused a significant increase of cohesiveness, while the addition of bamboo fibre caused a significant increase of adhesiveness (absolute value). In gels with pectin $0.4 \mathrm{~g} / 100 \mathrm{~g}$, fibre addition did not have a significant effect on hardness, while wheat fibre caused a significant increase of springiness. Fibre addition did not have a significant effect on springiness of gels with pectin $0.5 \mathrm{~g} / 100 \mathrm{~g}$. It caused a significant decrease of hardness (except bamboo fibre), and apple fibre caused a significant decrease of fracturability. 
Table 4. Mechanical parameters of the gels with pectin $0.4 \mathrm{~g} / 100 \mathrm{~g}$ (marked with 1) and $0.5 \mathrm{~g} / 100 \mathrm{~g}$ (marked with 2), and gels enriched with different types of fibre and combination of two types of fibre (1:1)

\begin{tabular}{|c|c|c|c|c|c|c|}
\hline Sample & Hardness/N & Fracturability/N & Cohesiveness & Gumminess/N & Adhesiveness/(N·s) & Springiness \\
\hline C1 & $(3.5 \pm 0.6)^{a, b}$ & $(2.3 \pm 0.6)^{\mathrm{b}}$ & $(0.13 \pm 0.05)^{\mathrm{a}}$ & $(0.5 \pm 0.2)^{\mathrm{a}, \mathrm{b}}$ & $(-1.5 \pm 0.3)^{c, d, e}$ & $(0.6 \pm 0.1)^{\mathrm{b}}$ \\
\hline A1 & $(5.8 \pm 1.1)^{\mathrm{b}, \mathrm{c}}$ & $(2.2 \pm 0.6)^{b}$ & $(0.12 \pm 0.03)^{\mathrm{a}}$ & $(0.7 \pm 0.2)^{a, b, c}$ & $(-3.0 \pm 0.5)^{b, c}$ & $(1.2 \pm 0.6)^{a, b}$ \\
\hline B1 & $(2.8 \pm 0.3)^{\mathrm{a}}$ & $(1.6 \pm 0.7)^{\mathrm{b}}$ & $(0.11 \pm 0.07)^{\mathrm{a}}$ & $(0.3 \pm 0.2)^{\mathrm{a}}$ & $(-3.4 \pm 0.3)^{a, b}$ & $(1.2 \pm 0.7)^{\mathrm{a}, \mathrm{b}}$ \\
\hline P1 & $(1.7 \pm 0.7)^{\mathrm{a}}$ & - & $(0.66 \pm 0.08)^{b}$ & $(1.1 \pm 0.3)^{b, c}$ & $(-0.9 \pm 0.3)^{\mathrm{e}}$ & $(0.70 \pm 0.03)^{a, b}$ \\
\hline W1 & $(2.9 \pm 0.7)^{\mathrm{a}}$ & $(1.50 \pm 0.07)^{\mathrm{a}, \mathrm{b}}$ & $(0.11 \pm 0.01)^{\mathrm{a}}$ & $(0.3 \pm 0.1)^{\mathrm{a}}$ & $(-2.7 \pm 0.5)^{\mathrm{b}, \mathrm{c}}$ & $(1.7 \pm 0.2)^{\mathrm{a}}$ \\
\hline $\mathrm{C} 2$ & $(10.6 \pm 1.0)^{d}$ & $(4.6 \pm 1.0)^{c}$ & $(0.12 \pm 0.00)^{\mathrm{a}}$ & $(1.3 \pm 0.2)^{c}$ & $(-2.4 \pm 0.8)^{b, c, d, e}$ & $(1.3 \pm 0.4)^{\mathrm{a}, \mathrm{b}}$ \\
\hline$A 2$ & $(6.4 \pm 1.1)^{\mathrm{c}, \mathrm{B}}$ & $(2.4 \pm 0.5)^{\mathrm{b}, \mathrm{B}}$ & $(0.11 \pm 0.00)^{\mathrm{a}, \mathrm{A}}$ & $(0.7 \pm 0.2)^{\mathrm{a}, \mathrm{a}, \mathrm{b}, \mathrm{A}, \mathrm{A}, \mathrm{B}}$ & $(-2.5 \pm 0.4)^{b, c, c, d, C, D}$ & $(1.4 \pm 0.3)^{a, b, A}$ \\
\hline B2 & $(8.2 \pm 1.2)^{\mathrm{C}, \mathrm{d}, \mathrm{B}}$ & $(4.5 \pm 0.7)^{\mathrm{C,B}, \mathrm{C}}$ & $(0.12 \pm 0.03)^{\mathrm{a}, \mathrm{A}}$ & $(1.0 \pm 0.2)^{\mathrm{b}, \mathrm{C}, \mathrm{A}, \mathrm{B}, \mathrm{C}}$ & $(-4.7 \pm 0.5)^{\mathrm{a}, \mathrm{C}, \mathrm{D}}$ & $(0.73 \pm 0.04)^{\mathrm{a}, \mathrm{b}, \mathrm{A}}$ \\
\hline P2 & $(1.8 \pm 0.9)^{\mathrm{a}, \mathrm{A}}$ & - & $(0.68 \pm 0.01)^{\mathrm{b}, \mathrm{c}}$ & $(1.2 \pm 0.6)^{\mathrm{C}, \mathrm{A}, \mathrm{B}, \mathrm{C}}$ & $(-1.1 \pm 0.3)^{\mathrm{d}, \mathrm{e}, \mathrm{D}}$ & $(0.65 \pm 0.02)^{a, b, b}$ \\
\hline W2 & $(7.8 \pm 0.3)^{\mathrm{c}, \mathrm{B}}$ & $(4.34 \pm 0.06)^{C, B, C}$ & $(0.15 \pm 0.00)^{\mathrm{a}, \mathrm{A}}$ & $(1.21 \pm 0.01)^{c, A, B, B}$ & $(-3.8 \pm 1.0)^{a, b, a, B, B, C}$ & $(0.79 \pm 0.09)^{\mathrm{a}, \mathrm{b}, \mathrm{B}}$ \\
\hline$A B 2$ & $(5.9 \pm 1.3)^{A, B}$ & $(2.3 \pm 0.5)^{B}$ & $(0.10 \pm 0.02)^{\mathrm{A}}$ & $(0.6 \pm 0.2)^{\mathrm{A}}$ & $(-4.3 \pm 0.6)^{A, B}$ & $(0.6 \pm 0.1)^{\mathrm{B}}$ \\
\hline AW2 & $(7.9 \pm 0.8)^{\mathrm{B}}$ & $(4.7 \pm 1.1)^{c}$ & $(0.15 \pm 0.01)^{\mathrm{A}}$ & $(1.2 \pm 0.1)^{A, B, C}$ & $(-4.4 \pm 0.3)^{A, B}$ & $(0.61 \pm 0.01)^{\mathrm{B}}$ \\
\hline AP2 & $(4.1 \pm 2.6)^{A, B}$ & $(2.8 \pm 1.2)^{B, C}$ & $(0.34 \pm 0.09)^{\mathrm{B}}$ & $(0.9 \pm 1.4)^{A, B, C}$ & $(-2.5 \pm 0.6)^{C, D}$ & $(0.6 \pm 0.1)^{\mathrm{B}}$ \\
\hline BP2 & $(5.1 \pm 1.8)^{\mathrm{A}, \mathrm{B}}$ & $(4.4 \pm 1.3)^{\mathrm{B}, \mathrm{C}}$ & $(0.32 \pm 0.04)^{\mathrm{B}}$ & $(1.6 \pm 0.5)^{B, C}$ & $(-2.7 \pm 0.3)^{c}$ & $(0.75 \pm 0.04)^{\mathrm{B}}$ \\
\hline WP2 & $(5.6 \pm 1.5)^{A, B}$ & - & $(0.33 \pm 0.03)^{\mathrm{B}}$ & $(1.9 \pm 0.6)^{c}$ & $(-3.0 \pm 0.6)^{\mathrm{B}, \mathrm{C}}$ & $(0.69 \pm 0.05)^{\mathrm{B}}$ \\
\hline
\end{tabular}

Samples with a common letter are not significantly different ( $p>0.05$ ): lower case letters compare the first ten samples of the first column (from C1 to W2), upper case letters compare the last nine samples of the first column (from A2 to WP2); $C=$ control gel (without fibre), $A=a p p l e, B=b a m b o o$, $\mathrm{P}=$ psyllium and $\mathrm{W}=$ wheat fibre

The decrease in the gel hardness seems to be inversely proportional to fibre swelling (except for wheat fibre), suggesting that less compact fibre may have had a softening effect on the gels. Since swelling was measured at room temperature and starch granules swell at high temperatures (38), as those used during gels preparation, it is likely that the real swelling of wheat fibre (containing starch) in the gels was higher than its swelling measured in cold water, explaining its softening effect on the gels.

Simple observation shows that gels enriched with psyllium fibre were remarkably different from the other gels, in the sense that they looked more "gummy" in terms of visual aspect, mouthfeel and sense of touch. This difference was not clearly revealed in the viscoelastic properties of the gels, but seemingly it was reflected in some of the mechanical parameters, such as hardness, fracturability and cohesiveness, which were remarkably different for gels enriched with psyllium fibre (curiously, the gumminess was similar to the other gels). Furthermore, these gels were so different from commercial fruit jams that the use of psyllium fibre alone is not suitable for the development of healthy confectionary jams. However, it might be used in combination with other fibre, as will be analyzed next.

Fig. $3 \mathrm{~b}$ shows the force $v$ s time curves of gels enriched with single and mixed fibre. Statistical analysis of the mechanical properties (Table 4) showed that some parameters required transformation, namely logarithm for cohesiveness and gumminess, and square root for springiness. We found that fibre combinations had a significant effect on the mechanical properties of the gels. Gel enriched with apple and bamboo fibre mix did not show significant differences in any of the properties compared to the gel enriched with bamboo fibre only. It showed significant differences in adhesiveness (more negative) and springiness (lower) compared to the gel enriched with apple fibre only. Gel enriched with apple and wheat fibre mix did not show significant differences in any of the properties compared to the gel enriched with wheat fibre only. It showed significant differences in fracturability (higher), adhesiveness (more negative) and springiness (lower) compared to the gel enriched with apple fibre only. Gel enriched with apple and psyllium fibre mix showed significant differences in hardness (higher), fracturability (higher) and cohesiveness (lower) compared to the sample enriched with psyllium fibre only. It showed significant differences in cohesiveness (higher) and springiness (lower) compared to the sample enriched with apple fibre only. Gel enriched with bamboo and psyllium fibre mix showed significant differences in fracturability (higher), adhesiveness (more negative) and cohesiveness (lower) compared to the sample enriched only with psyllium fibre. It also showed significant differences in cohesiveness (higher) and adhesiveness (less negative) compared to the sample enriched only with bamboo fibre. Finally, the gel enriched with wheat and psyllium fibre mix showed significant differences only in cohesiveness (lower) compared to the sample enriched with psyllium fibre only. It also showed significant differences in fracturability (lower) and cohesiveness (higher) compared to the sample enriched with wheat fibre only.

One conclusion from these results is that when apple fibre was mixed with bamboo or wheat, the other two types of fibre (bamboo or wheat) dominated the mechanical properties of the enriched gels, which was probably because apple fibre had a lower insoluble fraction. Another conclusion is that when psyllium fibre was mixed with the other types of fibre, the mechanical properties of the enriched gels were intermediate between those with the single fibre. The most relevant (and significant) changes compared to the gel enriched with 
psyllium fibre only were the decrease in cohesiveness (when mixed with apple, bamboo or wheat fibre), increase in fracturability (when mixed with apple or bamboo fibre), and increase in hardness (when mixed with apple fibre). These properties (cohesiveness, fracturability and hardness) were previously associated with the "gummy" aspect of psyllium-enriched gels. Consequently, the changes observed in these properties when mixing psyllium with other type of fibre were a desired and positive result.

\section{Syneresis of fibre-enriched gels}

Syneresis was determined as the percentage of water lost from the gels in $24 \mathrm{~h}$ after the mechanical TPA test (Table 3 ). Statistical analysis indicated that syneresis data did not require any transformation. It was clear that pectin mass fraction, type of fibre, and the interaction between these factors had a significant effect on the syneresis of the gels. Decreasing the pectin mass fraction produced a significant increase in the syneresis of the gels, except for the ones with psyllium fibre, which did not show syneresis at all. It is expected that higher pectin mass fractions will increase the WHC of the pectin network, reducing water loss of the gels. Elimination of syneresis by the addition of psyllium fibre was attributed to its high WHC (Table 2). This may also be associated with the fact that gels with psyllium fibre did not fracture during the mechanical test, and also showed much higher cohesiveness than the other gels (see previous section).

Addition of bamboo fibre did not have a significant effect on the gel syneresis at both pectin mass fractions, while apple fibre caused a significant decrease. Addition of wheat fibre had a significant but opposite effect at both pectin mass fractions: it increased the gel syneresis at pectin $0.4 \mathrm{~g} / 100 \mathrm{~g}$, and decreased syneresis at pectin $0.5 / 100 \mathrm{~g}$. This is in agreement with the results of the evaluation of viscoelastic properties of the gels, suggesting that the interaction of wheat fibre with the pectin network was much more favourable at the higher pectin mass fraction.

Even though water loss is generally undesirable in food gels, as far as we know there are no reference values for syneresis of pectin gels, nor legal limits for fruit jams. According to the results obtained in this work (Table 3 ), a syneresis value of $10 \mathrm{~g} / 100 \mathrm{~g}$ seems a very reasonable upper limit for pectin gels. Using this value to determine the acceptability of fibre-enriched pectin gels, it turns out that gels with pectin $0.4 \mathrm{~g} / 100 \mathrm{~g}$ were unacceptable (syneresis $>10 \mathrm{~g} / 100 \mathrm{~g}$ ), except gels with psyllium fibre, which did not show syneresis. However, as previously stated, gels enriched with psyllium fibre were considered not suitable (from an organoleptic perspective) for the development of healthy confectionery jams. Consequently, the appropriate pectin mass fraction in fibre-enriched gels seems to be $0.5 \mathrm{~g} / 100 \mathrm{~g}$.

Syneresis results of gels enriched with combined fibre are shown in Table 3. Statistical analysis indicated that syneresis data did not require any transformation, and that fibre combination had a significant effect on gel syneresis. The most important result is that gels enriched with mixtures of psyllium and other types of fibre did not show any syneresis, as was the case with the gels enriched with psyllium fibre only. Gels enriched with mixes of apple and bamboo or apple and wheat fibre had a significantly higher syneresis than gels enriched with these types of fibre alone, and even higher than the $10 \mathrm{~g} / 100 \mathrm{~g}$ value proposed in this work as the limit of acceptability. As a conclusion, any of the fibre studied (apple, bamboo and wheat) should be combined with psyllium in order to reduce the gel syneresis, even eliminating it when mixed in equal proportions.

\section{Colour of fibre-enriched gels}

Table 3 shows colour parameters of gels with pectin 0.5 $\mathrm{g} / 100 \mathrm{~g}$. Statistical analysis indicated that only parameter $a^{*}$ required a square root transformation. In all cases fibre addition significantly decreased the value of $L^{*}$ (darker gels), and significantly increased the value of $a^{*}$ (more reddish gels), apple being the fibre that produced the biggest changes. Regarding parameter $b^{*}$, significant changes were only produced by bamboo fibre (decrease) and psyllium fibre (increase; more yellowish gels).

Statistical analysis of the colour results of the gels enriched with combined fibre (Table 3 ) indicated that only $a^{*}$ values required a square root transformation. It was clear that combination of fibre had a significant effect on the three colour parameters. Gels with mixed apple and bamboo, apple and wheat, and apple and psyllium fibre showed the same significant effects: (i) higher $L^{*}$ values and lower $a^{*}$ and $b^{*}$ values than the gel with apple fibre only, and (ii) lower $L^{*}$ and $b^{*}$ values, and higher $a^{*}$ values than gels with bamboo, wheat and psyllium fibre only. Finally, gels with mixed bamboo and psyllium, and wheat and psyllium fibre had significantly lower $L^{*}$ and $b^{*}$ values than gels with psyllium, bamboo and wheat fibre only, while $a^{*}$ values were significantly lower than sample with psyllium fibre and higher than samples with bamboo or wheat fibre. Probably the most important conclusion of these results is that combination of apple with other types of fibre gave less dark gels than those enriched with apple fibre only, which was one of the objectives of combining different types of fibre.

\section{Microstructure of fibre-enriched gels}

Microstructure of fibre-enriched gels (Fig. 4) depended on the fibre source, as well as their physical (size, shape and colour) and chemical (solubility) characteristics. Particles observed in the micrographs correspond to the insoluble fraction of each fibre (Table 1). Fig. 4a shows the distribution of apple fibre particles in the gel matrix. These particles showed an irregular shape with rounded borders (9), grainy morphology (39), and a brown-yellowish colour. Fig. $4 \mathrm{~b}$ shows the micrograph of psyllium fibre. These particles have an irregular shape and a wider structure, which may be due to the mucilage formation, related to the high water absorption capacity of the fibre (black circles correspond to air bubbles formed during preparation 

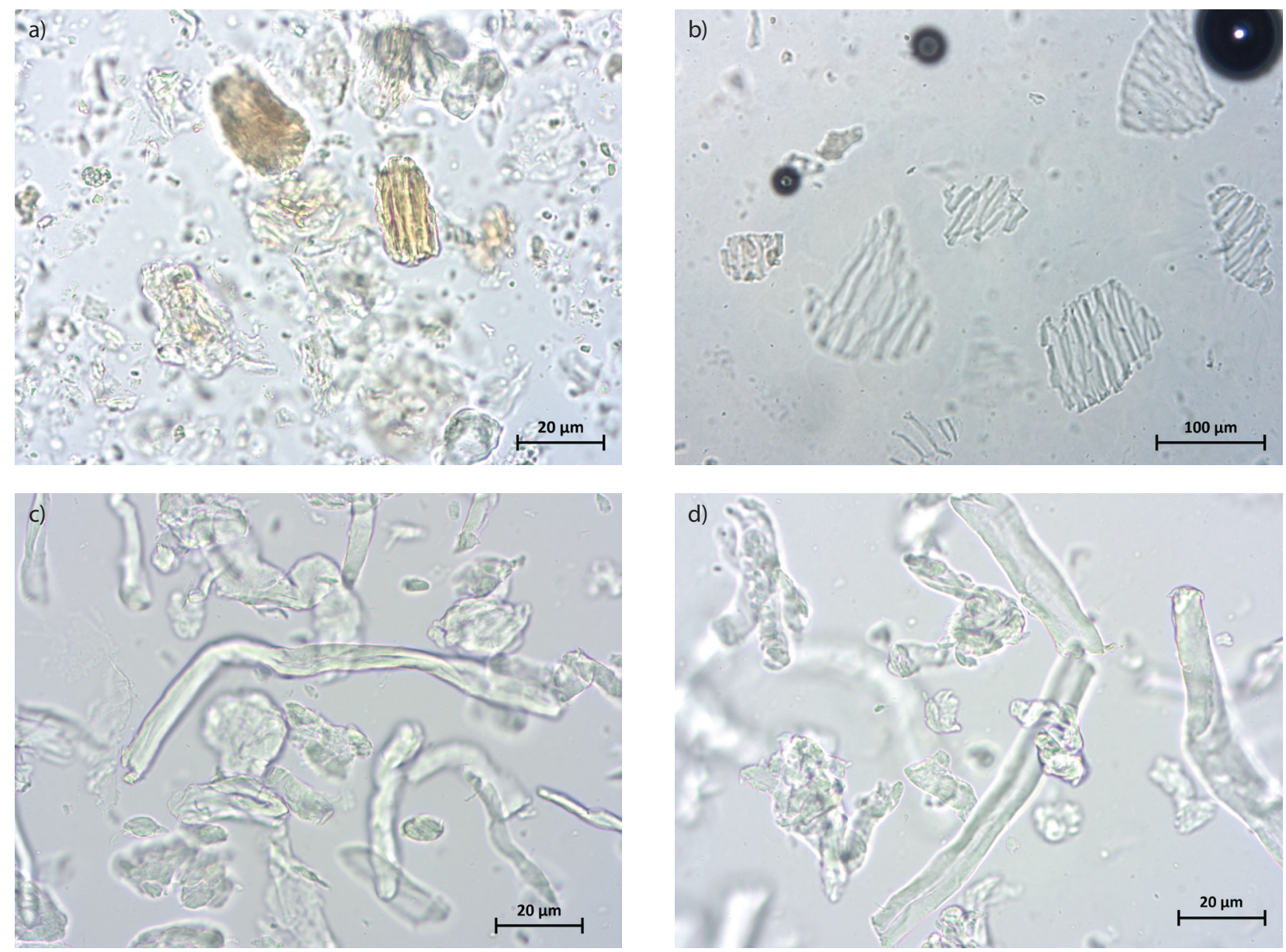

Fig. 4. Micrographs of pectin gels enriched with different types of fibre: a) apple, b) psyllium, c) bamboo and d) wheat

of the hot dispersion). Finally, gels enriched with bamboo and wheat fibre showed a similar microstructure (Figs. 4c and $4 d$, respectively). It is clear in both cases that particles have an elongated shape, as previously reported $(9,40)$.

The $d_{m}$ of hydrated fibre (Table 2 ) seems to be bigger than the size of the corresponding particles observed in Fig. 4. This could be due to particle attrition during preparation of the hot dispersion, where they were subjected to agitation and heat.

\section{CONCLUSIONS}

Unlike commercial fruit jams, fibre-enriched gels studied in this work can be declared as "source of fibre", and are the basis for the production of healthy confectionery jams with this label claim. Furthermore, the possibility of using fibre from non-fruit sources allows to increase the insoluble fraction of fibre in the final product. Viscoelastic properties increased with the increase of pectin mass fraction and fibre addition. The effect of these factors on the mechanical properties depended on the type of fibre. Syneresis decreased with the increase of pectin mass fraction, while the effect of fibre addition depended on the type of fibre. Gels with psyllium fibre did not show syneresis at all, but their overall aspect was too "gummy". This characteristic seemed to be associated mainly with three mechanical properties: lack of fracturability, high cohesiveness and low hardness. On the other hand, gels with apple fibre were too dark, and gels with bamboo and wheat fibre had a floury mouthfeel. These organoleptic properties were improved by mixing two different types of fibre in 1:1 ratio. This also reduced the viscoelastic properties of the gels, but not significantly in most of the cases. Particularly favourable results were obtained with the mix of psyllium with another type of fibre, because this reverted the mechanical properties of the gel enriched with psyllium fibre only (indicating a less "gummy" gel), keeping the syneresis at $0 \mathrm{~g} / 100 \mathrm{~g}$. Therefore, gels with pectin $0.5 \mathrm{~g} / 100 \mathrm{~g}$ enriched with psyllium mixed with apple, bamboo or wheat fibre seem to be the most recommendable for further development of healthy confectionery jams.

\section{ACKNOWLEDGEMENTS}

This work was supported by Consejo Nacional de Investigaciones Científicas y Técnicas (PIP 2015-2017 № 0156), Agencia Nacional de Promoción Científica y Técnica (PICT $2011 \mathrm{~N}^{\circ}$ 0680), and Universidad Nacional del Sur (PGI 24/M152), Argentina. We would like to thank Dr Marina Dello Staffolo for providing fibre samples. 


\section{REFERENCES}

1. Codex Alimentarius: Food Labelling. Rome, Italy: Food and Agriculture Organization of the United Nations and World Health Organization (FAO/WHO). 2007. Avaible from: http://www.fao.org/tempref/codex/Publications/Booklets/Labelling/Labelling_2007_EN.pdf.

2. Dhingra $D$, Michael $M$, Rajput $H$, Patil RT. Dietary fibre in foods: A review. J Food Sci Technol. 2012;49(3):255-66. https://doi.org/10.1007/s13197-011-0365-5

3. Mudgil D, Barak S. Composition, properties and health benefits of indigestible carbohydrate polymers as dietary fiber: A review. Int J Biol Macromol. 2013;61:1-6. https://doi.org/10.1016/j.ijbiomac.2013.06.044

4. Redgwell RJ, Fischer M. Dietary fiber as a versatile food component: An industrial perspective. Mol Nutr Food Res. 2005; 49(6):521-35.

https://doi.org/10.1002/mnfr.200500028

5. Rodríguez R, Jiménez A, Fernández-Bolaños J, Guillén R, Heredia A. Dietary fibre from vegetable products as source of functional ingredients. Trends Food Sci Technol. 2006; 17(1):3-15.

https://doi.org/10.1016/j.tifs.2005.10.002

6. Brownlee IA. The physiological roles of dietary fibre. Food Hydrocoll. 2011;25(2):238-50.

https://doi.org/10.1016/j.foodhyd.2009.11.013

7. Teixeira Macagnan F, Picolli da Silva L, Hecktheuer LH. Dietary fibre: The scientific search for an ideal definition and methodology of analysis, and its physiological importance as a carrier of bioactive compounds. Food Res Int. 2016;85:144-54.

https://doi.org/10.1016/j.foodres.2016.04.032

8. Institute of Medicine. Dietary reference intakes for energy, carbohydrate, fiber, fat, fatty acids, cholesterol, protein and amino acids. Washington, DC, USA:The National Academies Press, 2005.

https://doi.org/10.17226/10490

9. Rosell CM, Santos E, Collar C. Physico-chemical properties of commercial fibres from different sources: A comparative approach. Food Res Int. 2009;42(1):176-84.

https://doi.org/10.1016/j.foodres.2008.10.003

10. Cappa C, Lavelli V, Mariotti M. Fruit candies enriched with grape skin powders: Physicochemical properties. LWT Food Sci Technol. 2015;62(1):569-75.

https://doi.org/10.1016/j.lwt.2014.07.039

11. Grigelmo-Miguel N, Martín-Belloso O. Influence of fruit dietary fiber addition on physical and sensorial properties of strawberry jams. J Food Eng. 1999;41(1):13-21. https://doi.org/10.1016/S0260-8774(99)00067-9

12. Igual M, Contreras C, Martínez-Navarrete N. Colour and rheological properties of non-conventional grapefruit jams: Instrumental and sensory measurement. LWT - Food Sci
Technol. 2014;56(1):200-6.

https://doi.org/10.1016/j.lwt.2013.10.038

13. Grigelmo-Miguel N, Martín-Belloso O. The quality of peach jams stabilized with peach dietary fiber. Eur Food Res Technol. 2000;211(5):336-41.

https://doi.org/10.1007/s002170000172

14. Igual M, Contreras C, Martínez-Navarrete N. Non-conventional techniques to obtain grapefruit jam. Innov Food Sci Emerg Technol. 2010;11(2):335-41.

https://doi.org/10.1007/s002170000172

15. Genovese DB, Ye A, Singh H. High methoxyl pectin/apple particles composite gels: Effect of particle size and particle concentration on mechanical properties and gel structure. J Texture Stud. 2010;41(2):171-89.

https://doi.org/10.1111/j.1745-4603.2010.00220.x

16. Argentine Food Code. Dietary or regimen foods. Buenos Aires, Argentina: Nacional Administration of Drugs, Food and Medical Technology (ANMAT);2017. Available from: http://www.anmat.gov.ar/alimentos/codigoa/CAPITULO_XVII.pdf

17. Garrido Jl, Lozano JE, Genovese DB. Effect of formulation variables on rheology, texture, colour, and acceptability of apple jelly: Modelling and optimization. LWT - Food Sci Technol. 2015;62(1):325-32.

https://doi.org/10.1016/j.lwt.2014.07.010

18. Murúa-Pagola B, Beristain-Guevara $\mathrm{Cl}$, Martínez-Bustos F. Preparation of starch derivatives using reactive extrusion and evaluation of modified starches as shell materials for encapsulation of flavoring agents by spray drying. J Food Eng. 2009;91(3):380-6.

https://doi.org/10.1016/j.jfoodeng.2008.09.035

19. Jinapong N, Suphantharika M, Jamnong P. Production of instant soymilk powders by ultrafiltration, spray drying and fluidized bed agglomeration. J Food Eng. 2008;84(2):194205.

https://doi.org/10.1016/j.jfoodeng.2007.04.032

20. Raghavendra SN, Ramachandra Swamy SR, Rastogi NK, Raghavarao KSMS, Kumar S, Tharanathan RN. Grinding characteristics and hydration properties of coconut residue: A source of dietary fiber. J Food Eng. 2006;72(3):281-6. https://doi.org/10.1016/j.jfoodeng.2004.12.008

21. Robertson JA, de Monredon FD, Dysseler P, Guillon F, Amado R, Thibault JF. Hydration properties of dietary fibre and resistant starch: A European collaborative study. LWT Food Sci Technol. 2000;33(2):72-9. https://doi.org/10.1006/fstl.1999.0595

22. Cepeda E, Collado I. Rheology of tomato and wheat dietary fibers in water and in suspensions of pimento purée. J Food Eng. 2014;134:67-73.

https://doi.org/10.1016/j.jfoodeng.2014.03.007 
23. Thakur BR, Singh RK, Handa AK, Rao MA. Chemistry and uses of pectin - A review. Crit Rev Food Sci Nutr. 1997;37(1):47-73. https://doi.org/10.1080/10408399709527767

24. AOAC Official Method 991.43. Total, soluble, and insoluble dietary fibre in foods. Rockville, MD, USA: AOAC International; 1995.

25. Bourne MC. Principles of objective texture measurement. In:Taylor SL, editor. Food texture and viscosity: Concept and measurement. San Diego, CA, USA: Academic Press; 2002. pp. 182-6.

https://doi.org/10.1016/B978-012119062-0/50004-8

26. Einhorn-Stoll U. Pectin-water interactions in foods - From powder to gel. Food Hydrocoll. 2017;78:109-19. https://doi.org/10.1016/j.foodhyd.2017.05.029

27. InfoStat, Grupo InfoStat FCA, National University of Córdoba, Córdoba, Argentina; 2014. Avaible from: https://www. infostat.com.ar.

28. Design-Expert, v. 7.0.0, Stat-Ease Inc, Minneapolis, MN, USA; 2005. Avaible from: https://www.statease.com/.

29. Saeedi M, Morteza-Semnani K, Ansoroudi F, Fallah S, Amin G. Evaluation of binding properties of Plantago psyllium seed mucilage. Acta Pharm. 2010;60(3):339-48. https://doi.org/10.2478/v10007-010-0028-5

30. Robertson JA, Eastwood MA. An investigation of the experimental conditions which could affect water-holding capacity of dietary fibre. J Sci Food Agric. 1981;32(8):819-25. https://doi.org/10.1002/jsfa.2740320811

31. Thibault JF, Lahaye M, Guillon F. Physico-chemical properties of food plant cell walls. In: Schweizer TF, Edwards CA, editors. Dietary fibre - A component of food - Nutritional function in health and disease. London, UK: Springer-Verlag; 1992. pp. 21-39.

https://doi.org/10.1007/978-1-4471-1928-9_2

32. Ho YY, Lin CM, Wu MC. Evaluation of the prebiotic effects of citrus pectin hydrolysate. J Food Drug Anal. 2017;25(3):550-8. https://doi.org/10.1016/j.jfda.2016.11.014
33. Löfgren $\mathrm{C}$, Guillotin E, Evenbratt $\mathrm{H}$, Schols H, Hermansson AM. Effects of calcium, $\mathrm{pH}$, and blockiness on kinetic rheological behavior and microstructure of $\mathrm{HM}$ pectin gels. Biomacromolecules. 2005;6(2):646-52.

https://doi.org/10.1021/bm049619+

34. Löfgren C, Walkenström P, Hermansson AM. Microstructure and rheological behavior of pure and mixed pectin gels. Biomacromolecules. 2002;3(6):1144-53. https://doi.org/10.1021/bm020044v

35. Genovese DB. Shear rheology of hard-sphere, dispersed, and aggregated suspensions, and filler-matrix composites. Adv Colloid Interface Sci. 2012;171-172:1-16. https://doi.org/10.1016/j.cis.2011.12.005

36. Lopes da Silva JA, Rao MA. Rheological behavior of food gels. In: Anandha Rao M, editor. Rheology of fluid and semisolids foods. Food Engineering Series. Boston, MA, USA: Springer; 2007. pp. 339-401. https://doi.org/10.1007/978-0-387-70930-7_6

37. Dello Staffolo M, Bevilacqua AE, Rodríguez MS, Albertengo L. Dietary fiber and availability of nutrients: A case study on yoghurt as a food model. In: Karunaratne DN, editor. The complex world of polysaccharides. London, UK: IntechOpen Limited; 2012. pp. 455-90. https://doi.org/10.5772/54031

38. Genovese DB, Rao MA. Role of starch granule characteristics (volume fraction, rigidity, and fractal dimension) on the rheology of starch dispersions with and without amylose. Cereal Chem. 2003;80(3):350-5. https://doi.org/10.1094/CCHEM.2003.80.3.350

39. Akalın AS, Kesenkas H, Dinkci N, Unal G, Ozer E, Kınık O. Enrichment of probiotic ice cream with different dietary fibers: Structural characteristics and culture viability. J Dairy Sci. 2018;101(1):37-46. https://doi.org/10.3168/jds.2017-13468

40. Soukoulis C, Lebesi D, Tzia C. Enrichment of ice cream with dietary fibre: Effects on rheological properties, ice crystallisation and glass transition phenomena. Food Chem. 2009; 115(2):665-71.

https://doi.org/10.1016/j.foodchem.2008.12.070 
